\title{
$\widehat{A}$ Madridge
}

\section{madridge Journal of Dermatology \& Research}

Interconnecting scie

Open Access

\section{The Bork-Baykal Phenomenon}

\author{
Safae Zinoune ${ }^{\star}$ Hannane Baybay, Cheymae Saadani Hassani, Sara Elloudi and Fatima-Zahra Mernissi \\ Department of Dermatology, University Hospital Hassan II, Fez, Morocco
}

\section{Article Info}

\section{*Corresponding author:}

\section{Safae Zinoune}

Department of Dermatology

University Hospital Hassan II

Fez

Morocco

E-mail:dr.zinounesafae@gmail.com

Received: February 24, 2019

Accepted: February 26, 2019

Published: March 5, 2019

Citation: Zinoune S, Baybay H, Hassani CS, Elloudi S, Mernissi FZ. The Bork-Baykal Phenomenon. Madridge J Dermatol Res. 2019; 4(1): 88-89.

doi: $10.18689 / \mathrm{mjdr}-1000122$

Copyright: ( 2019 The Author(s). This work is licensed under a Creative Commons Attribution 4.0 International License, which permits unrestricted use, distribution, and reproduction in any medium, provided the original work is properly cited.

Published by Madridge Publishers
A 9-month-old boy referred to our department for evaluation of a giant melanocytic nevus of the trunk, which appeared since birth (Figures 1 and 2).
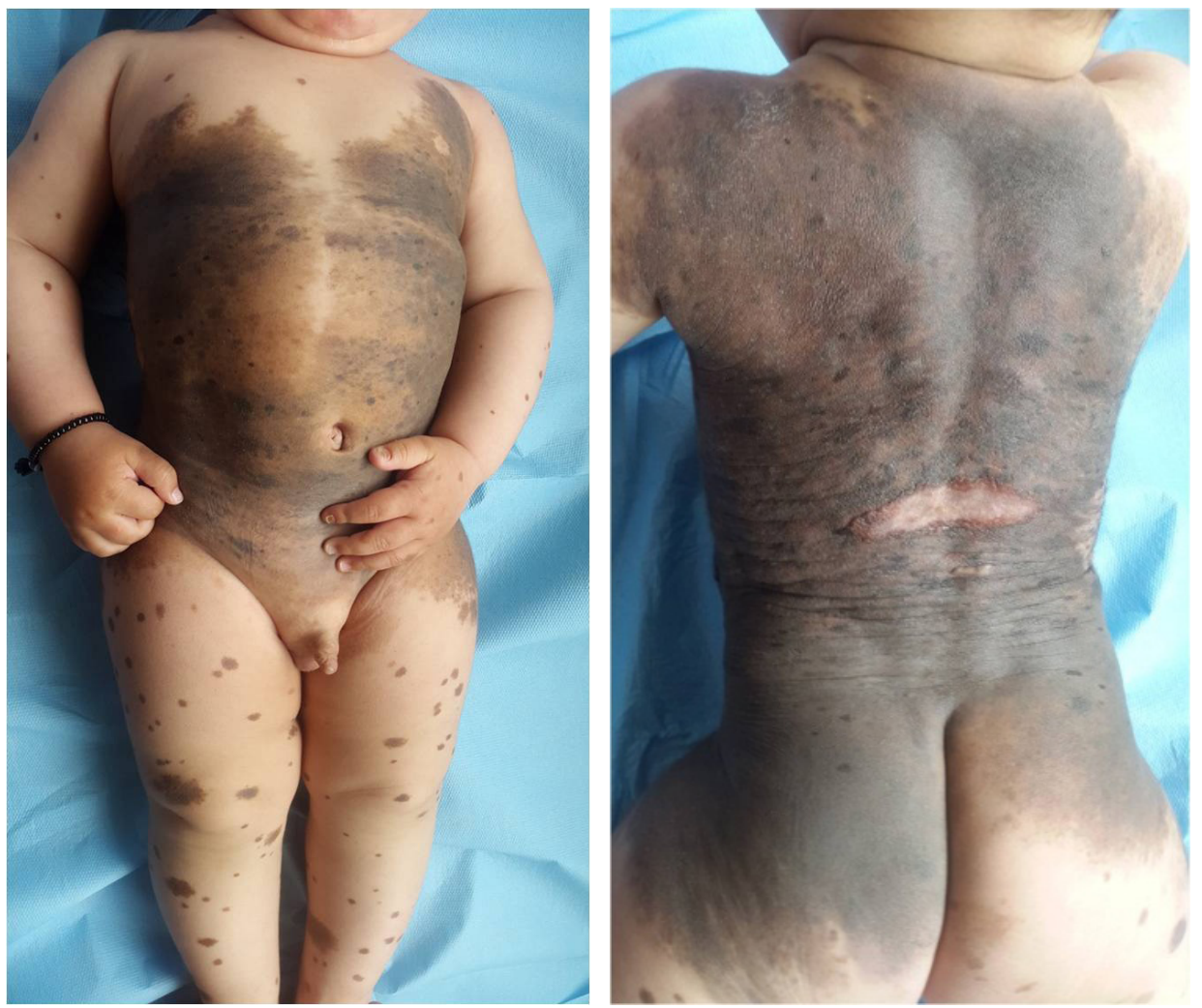

Figures 1 and 2. Circumferential giant melanocytic nevus of trunk with satellite elements.

The parents noticed a progressive extension of the lesion and the appearance of new satellite elements. The dermatological examination had objective a circumferential giant Congenital Melanocytic Nevus (CMN) of trunk surrounded the nipple-areola complexes but spared these structures with multiple satellite nevi. Dermoscopy of nipples revealed a homogeneous pigmented reticular pattern around of the areolas.

The Bork-Baykal phenomenon [1] is a special clinical appearance recently described on large congenital melanocytic nevi (LCMN) that corresponds to a CMN involving the breast but sparing the nipple and areola region, giving rise to the appearance of circular light-colored islands surrounded by the dark-brown or black color of the nevus [2].

This sparing phenomenon occurs in both sexes, remains unchanged during adolescence and adulthood, and may be noted either on both breasts or on one breast only. On rare occasions, only the nipples are spared, whereas the areola is involved by the LCMN. In cases of bilateral Bork-Baykal phenomenon, the extent of sparing may be markedly asymmetrical [3]. 
Similar to the mechanism of development of the divided nevus of the eyelid and penis, the different embryological time periods of the occurrence of LCMN and the development of the nipple-areola complex may explain the sparing phenomenon [2]. After the formation of mammary ridges, that occurs in the $4^{\text {th }}$ gestational week, development of the breast starts at the $5^{\text {th }}$ week. Although epidermal cells derived from the mammary ridges are confined to the area of the mammary pit as a plaque, the areola develops in the late fetal period around the $20^{\text {th }}$ week. The nipple, which is often depressed and poorly formed during infancy, forms during the perinatal period because of proliferation of the mesenchyme under the areola in the area of the mammary pit. The occurrence of the melanocytic lesion before embryologic development of nipple-areola complex would support this phenomenon [2].

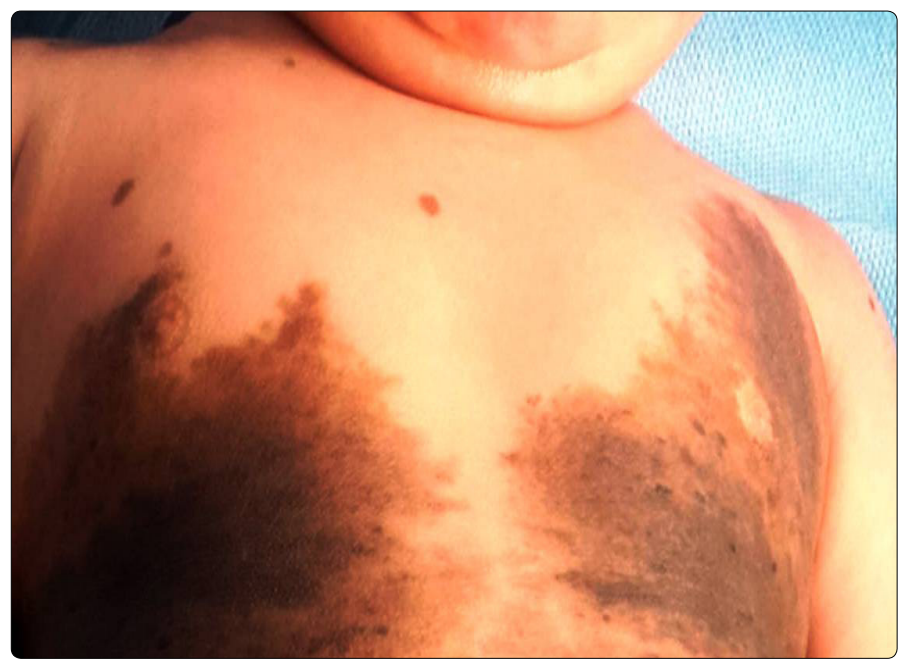

Figure 3. Giant congenital melanocytic nevus with sharp demarcation around the nipple-areola complexes.

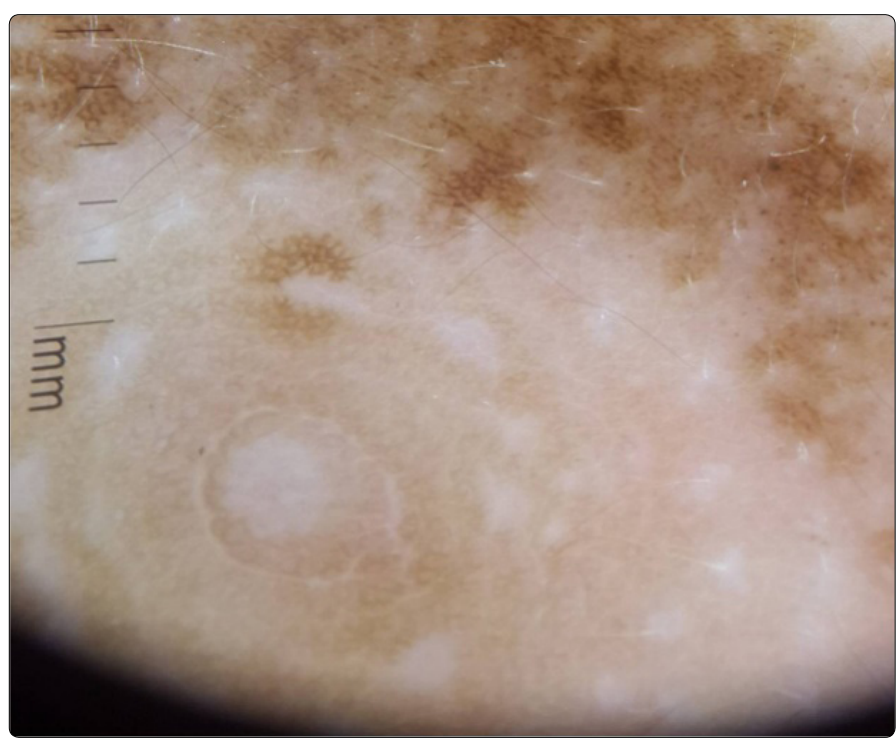

Figure 4. Brown network areas sparing the nipple-areola complex.

\section{Conflict of Interest}

No conflicts of interest.

\section{References}

1. Happle R. The Bork-Baykal phenomenon: a revised eponymic designation for the sparing of nipple and areola in large melanocytic nevi involving the breast. J Eur Acad Dermatol Venereol. 2017; 31(4): e214. doi: 10.1111/ jdv.13972

2. Baykal C, Solakoğlu S, Polat Ekinci A, Yazganoğlu KD. Large congenital melanocytic nevus on the breast sparing the nipple and areola. Pediatr Dermatol. 2015; 32(4): 514-517. doi: 10.1111/pde.12610

3. Happle R. The Baykal phenomenon: large congenital melanocytic nevi involving the breast tend to spare the nipple and areola. J Eur Acad Dermatol Venereol. 2015; 30(12): e181-e183. doi: 10.1111/jdv.13493 